\title{
Metformin regulates the incretin receptor axis via a pathway dependent on peroxisome proliferator-activated receptor- $\alpha$ in mice
}

\author{
A. Maida • B. J. Lamont $\cdot$ X. Cao • D. J. Drucker
}

Received: 7 August 2010 /Accepted: 6 September 2010 /Published online: 23 October 2010

(C) Springer-Verlag 2010

\begin{abstract}
Aims/hypothesis Metformin is widely used for the treatment of type 2 diabetes. Although it reduces hepatic glucose production, clinical studies show that metformin may reduce plasma dipeptidyl peptidase-4 activity and increase circulating levels of glucagon-like peptide 1 (GLP-1). We examined whether metformin exerts glucoregulatory actions via modulation of the incretin axis.

Methods Metformin action was assessed in $\mathrm{Glplr}^{-/-}, \mathrm{Gipr}^{-/-}$, Glp1r:Gipr ${ }^{--}$, Pparo (also known as Ppara) ${ }^{-/}$and hyperglycaemic obese wild-type mice with or without the GLP-1 receptor (GLP1R) antagonist exendin(9-39). Experimental endpoints included glucose tolerance, plasma insulin levels, gastric emptying and food intake. Incretin receptor expression was assessed in isolated islets from metformintreated wild-type and Ppard $^{-/-}$mice, and in INS-1 832/3 beta cells with or without peroxisome proliferator-activated receptor (PPAR)- $\alpha$ or AMP-activated protein kinase (AMPK) antagonists.
\end{abstract}

Electronic supplementary material The online version of this article (doi:10.1007/s00125-010-1937-z) contains supplementary material, which is available to authorised users.

A. Maida $\cdot$ D. J. Drucker

Institute of Medical Sciences, University of Toronto,

Toronto, ON, Canada

A. Maida $\cdot$ B. J. Lamont $\cdot$ X. Cao $\cdot$ D. J. Drucker

Samuel Lunenfeld Research Institute, University of Toronto,

Toronto, ON, Canada

\section{J. Drucker $(\bowtie)$}

Department of Medicine, Mt. Sinai Hospital SLRI,

600 University Avenue TCP5-1004,

Toronto, ON, Canada M5G 1X5

e-mail: d.drucker@utoronto.ca
Results In wild-type mice, metformin acutely increased plasma levels of GLP-1, but not those of gastric inhibitory polypeptide or peptide YY; it also improved oral glucose tolerance and reduced gastric emptying. Metformin significantly improved oral glucose tolerance despite loss of incretin action in $\mathrm{Glplr}^{-/-}, \mathrm{Gipr}^{-/-}$and $\mathrm{Glplr}^{-/}: \mathrm{Gipr}^{-/}$ mice, and in wild-type mice fed a high-fat diet and treated with exendin(9-39). Levels of mRNA transcripts for Glp1r, Gipr and Pparo were significantly increased in islets from metformin-treated mice. Metformin directly increased Glp1r expression in INS-1 beta cells via a PPAR- $\alpha-$ dependent, AMPK-independent mechanism. Metformin failed to induce incretin receptor gene expression in islets from Para $^{-1-}$ mice.

Conclusions/interpretation As metformin modulates multiple components of the incretin axis, and enhances expression of the Glplr and related insulinotropic islet receptors through a mechanism requiring PPAR- $\alpha$, metformin may be mechanistically well suited for combination with incretin-based therapies.

Keywords Dipeptidyl peptidase-4 · GIP. GLP-1 · Islets
Abbreviations
AICAR Aminoimidazole carboxamide ribonucleotide
AMPK AMP-activated protein kinase
DPP-4 Dipeptidyl peptidase-4
GIP Gastric inhibitory polypeptide
GLP-1 Glucagon-like peptide 1
GLP1R GLP-1 receptor
HBSS Hanks' balanced salt solution
LKB1 Liver kinase B1
PPAR Peroxisome proliferator-activated receptor 


\section{Introduction}

The biguanide metformin is the most commonly used agent in initial management of type 2 diabetes mellitus [1]. Although the mechanisms through which metformin exerts glucose-lowering actions are incompletely understood, treatment of diabetic patients with metformin reduced hepatic glucose production, primarily via decreased gluconeogenesis [2]. The molecular mechanisms mediating the actions of metformin on hepatic glucose production remain incompletely understood and are thought to involve engagement of the AMP-activated protein kinase (AMPK) pathway and its upstream kinase, liver kinase B1 (LKB1) $[3,4]$. Important roles for the cyclic AMP response element binding protein [5] and the transcription factor Kruppel-like factor 15 [6] have been proposed as molecular targets for the glucoregulatory actions of metformin. Understanding of metformin's mechanism of action is further complicated by the fact that it inhibits hepatic glucose production independently of AMPK and LKB1 [7, 8].

Metformin and glucagon play opposing roles in the control of hepatic glucose production. As type 2 diabetes mellitus is characterised by increased levels of glucagon and enhanced hepatic gluconeogenesis [9], there is considerable interest in reducing glucagon action in type 2 diabetes mellitus. Incretin-based therapies, the glucagonlike peptide 1 (GLP-1) receptor agonists and the dipeptidyl peptidase-4 (DPP-4) inhibitors, exert their actions in part via suppression of glucagon secretion from islet alpha cells [10]. Both GLP-1 receptor (GLP1R) agonists and DPP-4 inhibitors are widely used in combination with metformin, further amplifying the effects of these combinations on suppression of hepatic glucose production.

Unexpectedly, assessment of DPP-4 activity in plasma or serum from rodents or humans treated with metformin often reveals reduced DPP-4 activity [11-14]. In contrast, metformin does not directly inhibit DPP-4 activity in vitro $[15,16]$. Moreover, the biguanide compounds, metformin, phenformin and buformin, significantly increased plasma GLP-1 in normal rats and in F344/DuCrj rats with genetic DPP-4 deficiency, strongly suggesting that metformin increases GLP-1 levels independently of effects on DPP-4 activity [16]. These observations are consistent with human studies demonstrating that a single dose of metformin increases plasma levels of total, but not intact GLP-1 following oral glucose administration in non-diabetic patients [17]. Similarly, chronic therapy with metformin specifically increases plasma total GLP-1 levels in diabetic and non-diabetic participants [18].

Taken together, these observations suggest that metformin may exert some of its metabolic actions in part via amplification of incretin action. Accordingly, we examined the actions of metformin in wild-type and incretin receptor knockout mice. Our findings demonstrate that metformin increases plasma levels of GLP-1 and induces islet incretin receptor gene expression in vivo through a mechanism that is independent of AMPK, but dependent on peroxisome proliferator-activated receptor (PPAR)- $\alpha$.

\section{Methods}

Peptides and reagents

Metformin was from MP Biomedicals (Solon, OH, USA). Aminoimidazole carboxamide ribonucleotide (AICAR) was from Toronto Research Chemicals (North York, ON, Canada), the AMPK activator 5-(3-(4-(2-(4 fluorophenyl) ethoxy)phenyl)propyl) furan-2-carboxylic acid and compound $\mathrm{C}$ were from Calbiochem (Gibbstown, NJ, USA). Acetaminophen, MK-886, pyruvate, Hanks' balanced salt solution (HBSS), collagenase V, p-nitroaniline, aprotinin and diprotin A were from Sigma-Aldrich Canada (Oakville, ON, Canada). TRI reagent was from Molecular Research Center (Cincinnati, OH, USA). Exendin(9-39) was from Chi Scientific (Maynard, MA, USA).

\section{Animals}

All experiments were carried out with strict adherence to the Animal Protocols and Procedures approved by the Mount Sinai Hospital Animal Care Committee. C57BL/6 male mice (aged 10-14 weeks) were obtained from a colony originating from the Jackson Laboratory (Bar Harbor, ME, USA). For high-fat feeding studies, male C57BL/6 mice were fed a diet containing $58 \%$ of energy in fat, plus sucrose (D12331; Research Diets, New Brunswick, NJ, USA) for 10 to 12 weeks commencing at 8 weeks of age. Littermate $\mathrm{Glplr}^{-/-}, \mathrm{Gipr}^{-1-}, \mathrm{Glplr}^{-/-}: \mathrm{Gipr}^{-/-}$and corresponding wild-type mice on the C57BL/6 background were obtained by intercrossing $\mathrm{Glplr}^{+/-}$:Gipr $^{+-}$mice and genotyped as described [19]. Ppara (also known as Ppara $)^{-1-}$ mice were obtained from the Jackson Laboratory on the 129S4/SvJae background and backcrossed to the C57BL/6 background for seven generations before interbreeding Ppara ${ }^{+/}$mice for experiments.

Assessment of metformin action in mice with disrupted incretin receptor signalling

Glucose tolerance and food intake experiments had a crossover design, where the same mice were given vehicle or test agents on separate occasions spaced at least 1 week apart. For acute administration, metformin was administered in methylcellulose $(0.5 \%$ [wt/vol.] in distilled water). The AMPK activator 5-(3-(4-(2-(4-fluorophenyl)ethoxy) 
phenyl)propyl) furan-2-carboxylic acid was suspended in carboxymethylcellulose $(0.5 \%$ [wt/vol.] in distilled water). The GLP1R antagonist exendin(9-39) and AICAR were dissolved in PBS.

Glucose and pyruvate tolerance in animals fed regular chow Mice were fasted for $6 \mathrm{~h}(07: 30-13: 30$ hours $)$ and then given metformin or vehicle $(0.5 \%$ [wt/vol.] methylcellulose) $1 \mathrm{~h}$ prior to glucose or pyruvate administration. For OGTT, a solution containing glucose $(2 \mathrm{~g} / \mathrm{kg}$ for regular chow-fed mice, $1 \mathrm{~g} / \mathrm{kg}$ for mice on high-fat diet) and acetaminophen $(0.1 \mathrm{~g} / \mathrm{kg})$ was administered orally. For pyruvate tolerance tests, pyruvate, $2 \mathrm{~g} / \mathrm{kg}$, was dissolved in PBS and administered i.p. Blood glucose was sampled via tail vein using a glucometer (Bayer, Toronto, ON, Canada). For measurement of plasma hormones, blood was collected into EDTA-coated tubes containing aprotinin and diprotin A at final concentrations of $500 \mathrm{kIU} / \mathrm{ml}$ and $1 \mu \mathrm{mol} / \mathrm{l}$, respectively.

Food intake Singly housed, overnight-fasted mice were given metformin or vehicle orally $1 \mathrm{~h}$ prior to re-feeding and food weight was recorded at the indicated time-points.

Plasma hormones and acetaminophen Plasma insulin, peptide YY (both from Alpco Diagnostics, Salem, NH, USA) and gastric inhibitory polypeptide (GIP) (Millipore, Billerica, MA, USA) were determined by ELISA. Total GLP-1 was determined using an electrochemiluminescent sandwich immunoassay (Mesoscale Scale Discovery, Gaithersburg, MD, USA). Plasma acetaminophen was measured with an enzymatic assay (Genzyme Diagnostics, Charlottetown, PE, Canada). Plasma DPP-4 activity was determined by enzymatic assay [20].

The effect of metformin on islet incretin receptor expression

Subchronic metformin administration in mice Metformin was administered in the drinking water at a dose of $300 \mathrm{mg} / \mathrm{kg}$ daily for $48 \mathrm{~h}$. Water consumption and food intake were monitored and did not differ between mice treated with metformin and those treated by control. At $4 \mathrm{~h}$ prior to killing by $\mathrm{CO}_{2}$ asphyxiation mice were fasted and given an oral dose of metformin $(75 \mathrm{mg} / \mathrm{kg})$. Islets were isolated from a cohort of mice as described below. Pancreatic RNA was isolated from the splenic tail and stored at $-80^{\circ} \mathrm{C}$ until further analysis. Duodenal or colonic segments were flushed with saline, snap-frozen and stored at $-80^{\circ} \mathrm{C}$ until RNA isolation.

Islet isolation After mice were killed by $\mathrm{CO}_{2}$ asphyxiation, the pancreas was inflated via the pancreatic duct with collagenase type $\mathrm{V}(0.7 \mathrm{mg} / \mathrm{ml}$ in HBSS $)$, excised and digested at $37^{\circ} \mathrm{C}$ for 10 to $15 \mathrm{~min}$. The digest was washed twice with cold HBSS containing $0.25 \% \mathrm{wt} / \mathrm{vol} \mathrm{BSA}$ and islets were separated using a Histopaque density gradient. The interface containing islets was removed, washed with HBSS + BSA and islets further purified by hand-picking using a light microscope. Islets were washed once with PBS prior to lysis and RNA isolation with a kit (RNeasy Mini; Qiagen, Mississauga, ON, Canada).

INS-1 832/3 cell culture This clonal beta cell line was a kind gift from C. Newgard (Department of Pharmacology and Cancer Biology, Duke University, Raleigh, NC, USA). Cells were seeded in six-well plates at $2 \times 10^{6}$ cells/well $48 \mathrm{~h}$ prior to experiments. After a $6 \mathrm{~h}$ serum starvation period in the presence of RPMI media containing $5 \mathrm{mmol} / \mathrm{l}$ glucose and $0.1 \%(\mathrm{wt} / \mathrm{vol}$.) BSA, fresh medium was added containing 5 or $20 \mathrm{mmol} / \mathrm{l}$ glucose with or without metformin or AICAR. Inhibitors or vehicle (DMSO) were added 15 min prior to metformin or AICAR treatment. Cells were washed twice with PBS prior to lysis with TRI reagent. To determine the effect of chronic metformin treatment on incretin-stimulated insulin secretion, cells were seeded in 24 -well plates at $0.5 \times 10^{6}$ cells/well $48 \mathrm{~h}$ prior to experiments. Serum-free medium was added containing $5 \mathrm{mmol} / 1$ glucose and $0.1 \%$ (wt/vol.) BSA with or without metformin $(1 \mathrm{mmol} / \mathrm{l})$ and cells were incubated at $37^{\circ} \mathrm{C}$ for $24 \mathrm{~h}$ prior to assessment of insulin secretion as described previously [21]. Levels of secreted insulin were normalised to insulin content per well and expressed relative to high glucose.

RNA isolation and cDNA synthesis RNA was isolated from mouse tissues and INS-1 cells using TRI reagent. First-strand cDNA was synthesised from total RNA using a reverse transcriptase synthesis system (SuperScript III; Invitrogen, Carlsbad, CA, USA) and random hexamers. Real-time PCR was performed with a sequence detection system (ABI Prism 7900; Applied Biosystems, Foster City, CA, USA) using gene expression assays and Universal PCR Master Mix (TaqMan; Applied Biosystems). Levels of mRNA transcripts were normalised to peptidyl-propyl isomerase A (cyclophilin) for murine tissues and general transcription factor II B for rat INS$1832 / 3$ cells.

\section{Statistical analysis}

Results are presented as mean \pm SEM. Statistical significance was determined using one-way or two-way ANOVA with Bonferroni post hoc tests or $t$ tests (as appropriate) and GraphPad Prism 4.0 (GraphPad Software, La Jolla, CA, USA). In experiments with a crossover design, paired or 
repeated measures analysis was employed. Statistical significance was noted as given at $p<0.05$.

\section{Results}

Assessment of metformin action in mice with disrupted incretin receptor signalling

As metformin increases plasma levels of GLP-1 in humans and rats $[16,17]$, we determined whether oral dosing of metformin without concomitant glucose administration influenced plasma incretin levels in mice. Metformin significantly increased plasma GLP-1 at all doses compared with vehicle alone (Fig. 1a), with levels of total GLP-1 after the $300 \mathrm{mg} / \mathrm{kg}$ metformin dose similar to that achieved with enteral glucose administration (Fig. 1a). In contrast, levels of plasma GIP were unchanged or significantly decreased after metformin (Fig. 1b). Similarly, plasma levels of peptide YY, co-secreted with GLP-1 from subsets of L cells, remained unchanged after metformin administration (Electronic supplementary material [ESM] Fig. 1a).

As metformin exerts multiple metabolic actions via AMPK [3], we assessed whether pharmacological AMPK

b
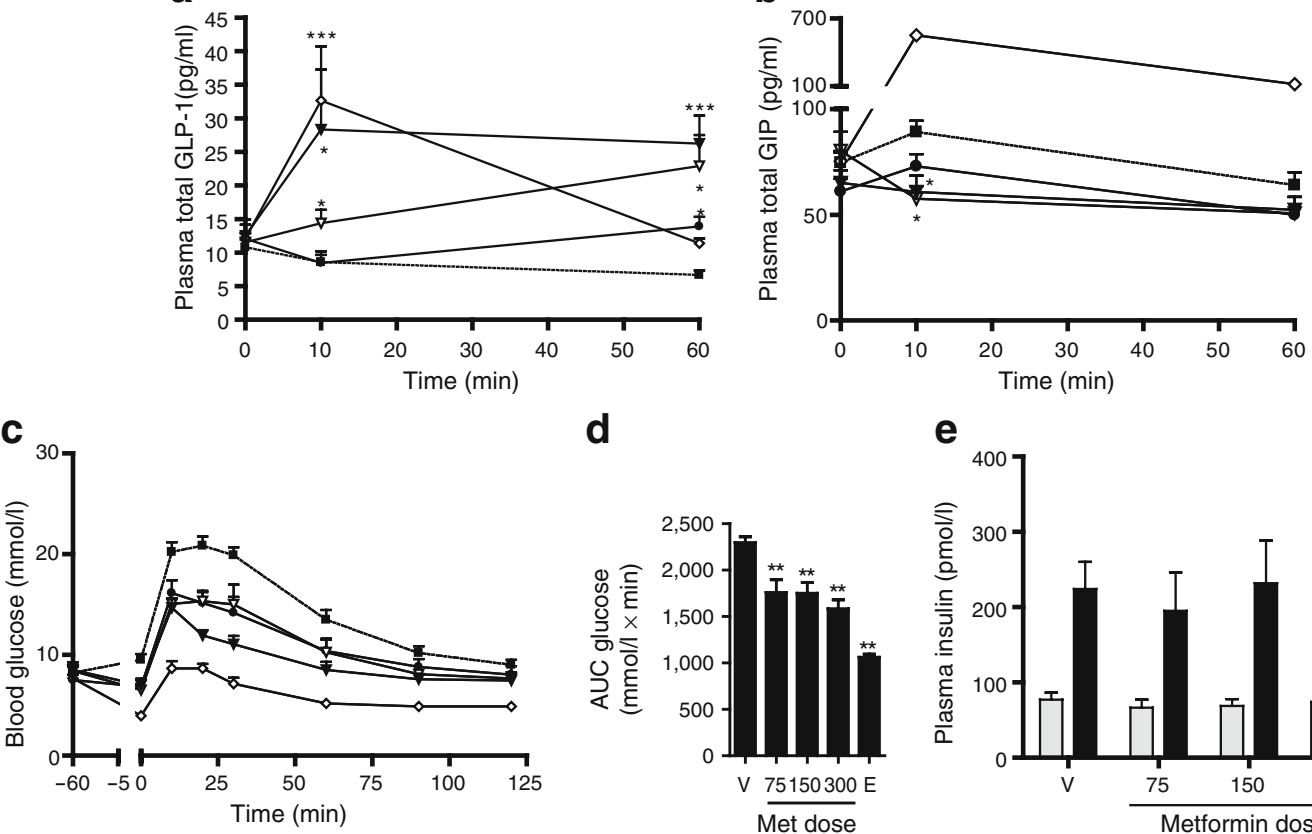

d

e

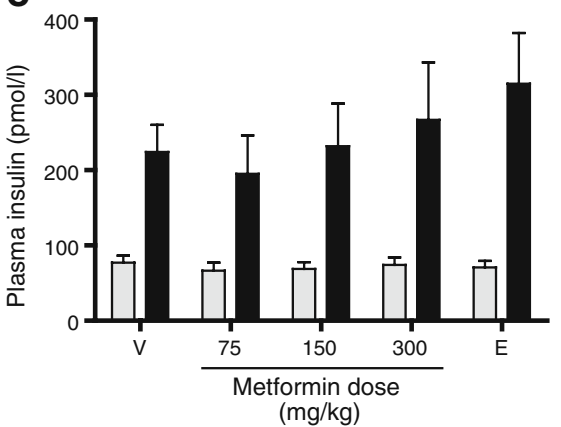

i

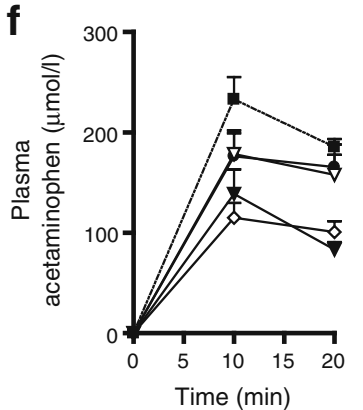

g

h
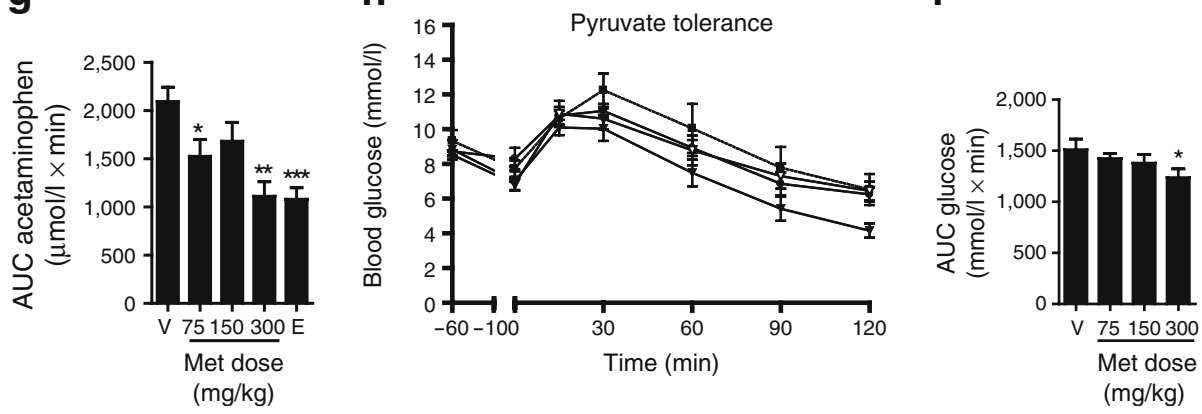

OGTT. d Mean AUC glucose for each treatment. V, vehicle; E, exendin-4. e Levels of plasma insulin and (f) plasma acetaminophen, a marker of gastric emptying, were quantified during the OGTT, with (g) AUC for acetaminophen. Grey bars (e), $0 \mathrm{~min}$; black bars, $10 \mathrm{~min}$. h Metformin or vehicle, key as above (a, b), was administered $1 \mathrm{~h}$ prior to administration of pyruvate (at $t=0$ ) and blood glucose levels were determined as an indirect assessment of hepatic glucose production, with AUC glucose (i). ${ }^{*} p<0.05,{ }^{* *} p<0.01$ and ${ }^{* * *} p<0.001$ vs vehicle; $n=5$ mice 
activation increased plasma GLP-1. Intraperitoneal injection of AICAR produced a robust elevation in plasma GLP-1 (15 vs $113 \mathrm{pg} / \mathrm{ml}, p<0.001)$ and a significant increase in plasma GIP (60 vs $116 \mathrm{pg} / \mathrm{ml}, p<0.05$ for vehicle vs AICAR) (ESM Fig. 1b, c). The orally active AMPK activator 5-(3-(4-(2-(4-fluorophenyl)ethoxy)phenyl)propyl) furan-2-carboxylic acid [22] tended to increase levels of plasma total GLP-1 $(p=0.07)$, but not of total GIP, to a lower degree relative to AICAR (ESM Fig. 1b, c). Doses of metformin $(75-300 \mathrm{mg} / \mathrm{kg})$ and AICAR that increased plasma levels of GLP-1 had no effect on plasma DPP-4 activity (ESM Fig. 1d).

To determine the extent to which metformin and GLP1R agonists share overlapping actions, we acutely administered metformin during an OGTT in wild-type mice. Metformin and the GLP1R agonist exendin-4 significantly reduced the AUC glucose (Fig. 1c, d), without changes in plasma insulin levels (Fig. 1e). As GLP1R activation improves oral glucose tolerance via a mechanism independent of insulin and involving inhibition of gastric emptying [23], we assessed gastric emptying via measurement of plasma acetaminophen [24]. Metformin ( 75 and $300 \mathrm{mg} / \mathrm{kg}$ ) significantly reduced the rate of gastric emptying (Fig. 1f, g). We next examined the effect of metformin on plasma glucose levels following pyruvate administration, an indirect assessment of hepatic glucose production. At the two lower doses that increased plasma GLP-1 and inhibited gastric emptying, metformin had no consistent effect on glucose appearance after pyruvate (Fig. 1h, i); however, at the highest dose $(300 \mathrm{mg} / \mathrm{kg}$ ), metformin significantly reduced pyruvateinduced glycaemic excursion (Fig. 1h, i).

We next ascertained whether the glucoregulatory actions of metformin required intact GLP-1 receptor signalling. The GLP1R antagonist exendin(9-39) impaired oral glucose tolerance in wild-type mice (ESM Fig. 2a-c). Furthermore, even the $75 \mathrm{mg} / \mathrm{kg}$ dose of metformin, which did not affect pyruvate tolerance, continued to lower blood glucose in the presence of exendin(9-39) (ESM Fig. 2b-c). Metformin did not affect OGTT plasma insulin levels in the presence or absence of exendin(9-39) (ESM Fig. 2d). In contrast, the GLP1R antagonist diminished the ability of metformin to reduce gastric emptying (ESM Fig. 2e).

As exendin(9-39) does not completely eliminate GLP-1 action, we tested the acute glucoregulatory actions of metformin in mice with genetic disruption of one or both incretin receptors. Metformin $(75 \mathrm{mg} / \mathrm{kg})$ significantly reduced glycaemic excursion following enteral glucose challenge; this happened independently of the GLP1R or GIP receptor (Fig. 2a-h). Levels of plasma insulin (Fig. 2i) and insulin:glucose ratios (ESM Fig. 3) were comparable in vehicle vs metformin-treated wild-type littermate, Glp1r ${ }^{-1-}$, $\mathrm{Gipr}^{--}$and $\mathrm{Glplr}^{-1-} \mathrm{Gipr}^{-1-}$ mice. While gastric emptying was slightly increased in $\mathrm{Glplr}^{-/-}$ and $\mathrm{Glplr}^{-1-}: \mathrm{Gipr}^{--}$mice vs corresponding wild-type controls, it was inhibited by metformin in these groups; unexpectedly, metformin failed to reduce gastric emptying in $\mathrm{Gipr}^{-/-}$mice (Fig. 2j). Plasma glucagon was reduced post-glucose administration independent of the presence of metformin or the GLP1R (ESM Fig. 4). Although metformin and GLP1R agonists such as exendin-4 are capable of reducing food intake (ESM Fig. 5), metformin significantly reduced food intake in a GLP1R-independent manner (Fig. 3).

To study the glucoregulatory actions of metformin under conditions of moderate insulin resistance and hyperglycaemia [25], we assessed glucose tolerance in wild-type C57BL/6 mice after 12 weeks on a high-fat diet (Fig. 4a). Fasting blood glucose was significantly increased in mice on a high-fat diet ( $12.3 \mathrm{vs} 8.4 \mathrm{mmol} / 1, p<0.001$ for high-fat diet vs regular chow-fed animals, respectively). In the same group, metformin significantly reduced glycaemic excursions (Fig. 4b, c), without changes in plasma insulin levels (Fig. 4d). Interruption of GLP1R signalling with exendin(9-39) alone increased the amplitude of glycaemic excursions; however, metformin continued to reduce glycaemic excursions in exendin(9-39)-treated mice on a high-fat diet (Fig. 4b, c). Metformin also tended to inhibit gastric emptying in the presence of the GLP1R antagonist; however, further experimentation is required to definitively determine whether GLP-1 contributes to the inhibitory effect of metformin on gastric emptying (Fig. 4e).

The effect of metformin on islet incretin receptor expression

As metformin upregulates the expression of incretin receptors in an islet cell line in vitro [26], we assessed whether metformin modulates pancreatic or islet incretin receptor expression in murine islets. Metformin-treated mice (Fig. 5a) had significantly increased levels of Gipr but no change in levels of Glp1r, Ppar $\alpha$ or insulin mRNA transcripts in RNA from whole pancreas (Fig. 5b). To ascertain the effects of metformin on gene expression in the endocrine pancreas, we isolated islets from metformintreated mice. Glp1r, Gipr and Ppara, but not insulin mRNA transcripts were significantly upregulated in islets from metformin-treated mice (Fig. 5c). To ascertain whether metformin exerted a direct effect on islet beta cells, we incubated INS-1 $832 / 3$ cells with or without metformin at 5 or $20 \mathrm{mmol} / \mathrm{l}$ glucose. Metformin had no direct effect on Gipr mRNA transcripts (Fig. 5d). However, a significant induction of Glp1r and Ppara mRNA transcripts was detected in metformin-treated INS- $1832 / 3$ cells at both glucose concentrations (Fig. 5d). In contrast, the AMPK activator AICAR reduced levels of Gipr and Glplr mRNA transcripts in INS-1 832/3 cells (Fig. 5e, f). 
a

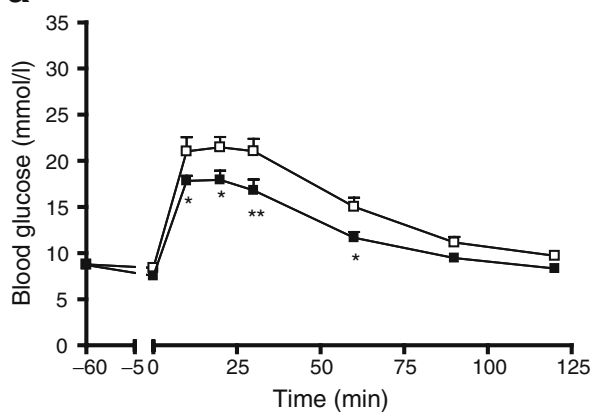

e

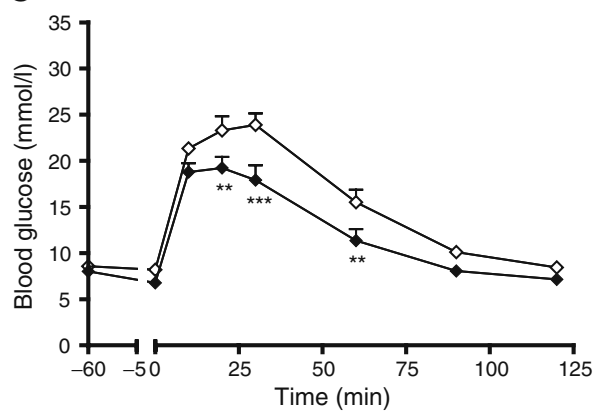

b

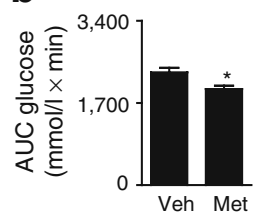

f

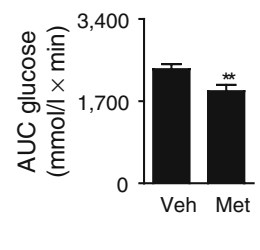

i

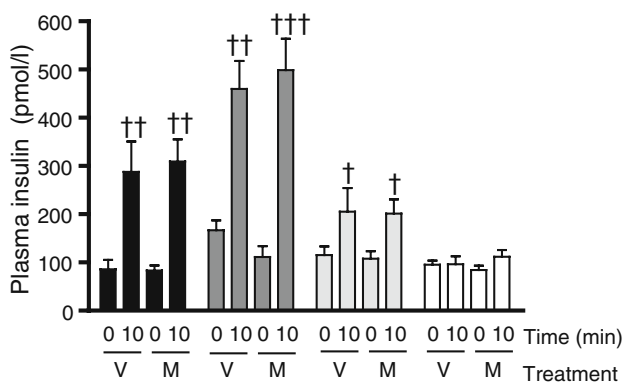

g
C

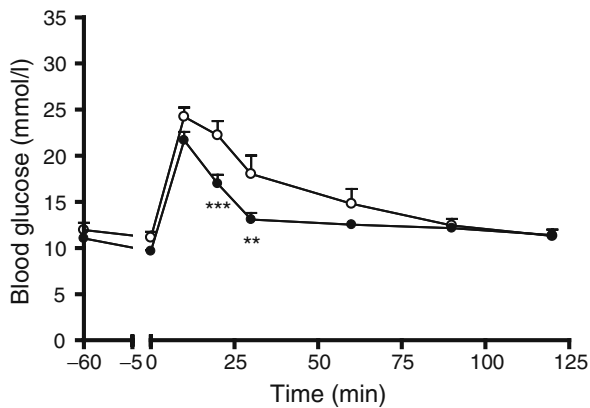

d
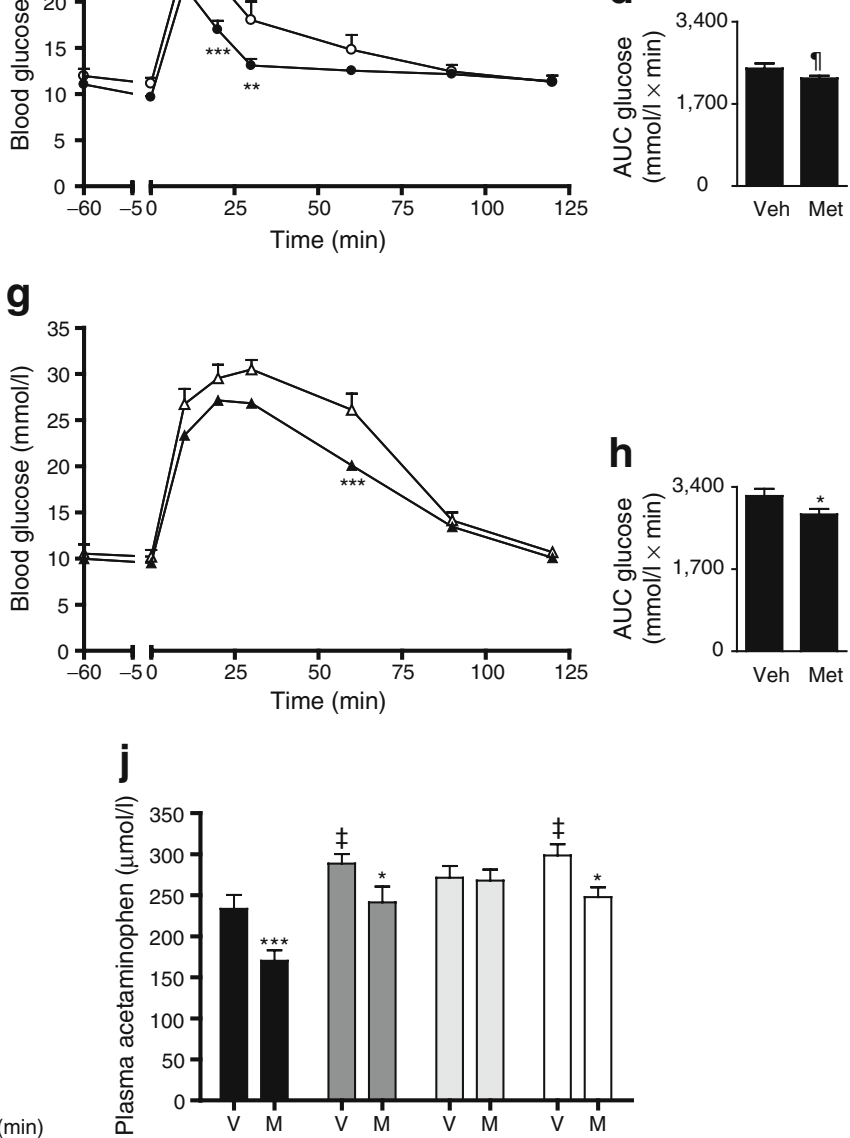

Fig. 2 Metformin reduces glycaemic excursions in single and double incretin receptor knockout mice. Glp1r ${ }^{-/}, \mathrm{Gipr}^{-/}, \mathrm{Glplr}^{-/-}: \mathrm{Gipr}^{--}$and wild-type littermates were administered metformin by oral gavage (black symbols; $75 \mathrm{mg} / \mathrm{kg}$ ) or vehicle (white symbols; $0.5 \% \mathrm{wt} / \mathrm{vol}$ methylcellulose) $1 \mathrm{~h}$ prior to OGTT. a Blood glucose concentrations in Glplr $^{+/+}: \mathrm{Gipr}^{+/+}$, with (b) AUC glucose, (c) Glplr ${ }^{-/-}: \mathrm{Gipr}^{+/+}$, with (d) AUC glucose, (e) Glplr ${ }^{+/+}:$Gipr $^{-/}$, with (f) AUC glucose, and (g) $\mathrm{Glp}_{1 r^{-/-}}: \mathrm{Gipr}^{-/-}$, with (h) AUC glucose. i Plasma insulin was quantified at $t=0$ (just prior to glucose administration) and $10 \mathrm{~min}$

To delineate mechanism(s) mediating the actions of metformin on islet incretin receptors, we treated INS-1 832/3 cells with the AMPK inhibitor, compound C. Consistent with the inability of AICAR to induce Glplr expression, inhibition of AMPK activity had no effect on the induction of Glplr mRNA by metformin (Fig. 5e) and reduced basal levels of Gipr mRNA transcripts (Fig. 5f). Although AICAR increased expression of Ppara in an AMPK-dependent manner in INS-1 832/3 cells, the inductive effects of AICAR on Ppar $\alpha$ were independent of PPAR- $\alpha$ activity (Fig. 5g). In contrast, the PPAR- $\alpha$ post-glucose. Black bars, Glp1r ${ }^{+/+}: \mathrm{Gipr}^{+/+}$; dark grey bars, Glp1r ${ }^{-/-}$: $\mathrm{Gipr}^{+/+}$; light grey bars, Glp1r ${ }^{+/+}: \mathrm{Gipr}^{-/-}$; white bars, Glplr $^{-/-}: \mathrm{Gipr}^{-/-}$; $\mathrm{V}$, vehicle; M, metformin. $\mathbf{j}$ Levels of plasma acetaminophen, an indirect marker of gastric emptying, were quantified at the $10 \mathrm{~min}$. ${ }^{*} p<0.05, * * p<0.01, * * * p<0.001$ and $\|^{*}=0.7$ vs vehicle-treated groups; ${ }^{\dagger} p<0.05,{ }^{\dagger} p<0.01$ and ${ }^{\dagger \dagger} p<0.001$ vs $t=0$ for the same treatment group; ${ }^{\star} p<0.05$ vs corresponding wild-type vehicle-treated group. $n=10-12$ mice

inhibitor MK-886 prevented induction of the Glp1r (Fig. 5e) and Ppara (Fig. 5g) mRNA transcripts by metformin. We next examined whether metformin treatment altered the sensitivity of INS- $1832 / 3$ cells to incretinstimulated insulin secretion. Interestingly, the relative effects of GIP and GLP-1 on insulin secretion were significantly increased by metformin treatment (Fig. 5h).

The demonstration that metformin induces islet Glplr gene expression in a PPAR- $\alpha$-dependent manner in islet cells in vitro prompted us to assess the importance of PPAR- $\alpha$ for the actions of metformin on islet gene 


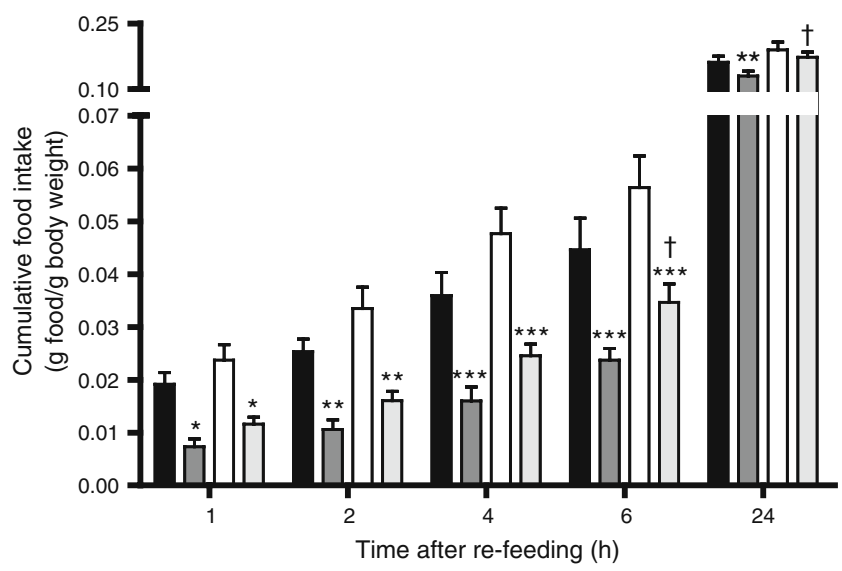

Fig. 3 Metformin reduces food intake in $\mathrm{Glplr}^{+/+}$and $\mathrm{Glplr}^{-/-}$mice. Food intake was measured in overnight fasted mice after administration of metformin $\left(300 \mathrm{mg} / \mathrm{kg}\right.$ ) (light grey bars, $\mathrm{Glplr}^{-1}$; dark grey bars, Glplr $r^{+/+}$) or vehicle (white bars, Glplr ${ }^{-1-}$; black bars, Glp $1 r^{+/+}$) by gavage $1 \mathrm{~h}$ prior to re-feeding. $* p<0.05, * * p<0.01$ and $* * * p<$ 0.001 vs vehicle-treated mice of the same genotype; ${ }^{\dagger} p<0.05$ vs GlpIr $^{+/+}$mice treated with metformin. $n=8-9$ expression in vivo. Metformin treatment of mice (Fig. 6a) increased expression of Gipr, Gcgr, Cckar and Insr, and tended to increase Glp1r mRNA transcripts in islets isolated from Ppard $^{+/+}$mice (Fig. 6b); this occurred independently of changes in food intake, blood glucose or body weight (data not shown). In contrast, metformin failed to increase islet Glp1r, Gipr, Gcgr, Cckar and Insr mRNA transcripts in Ppard $^{-/-}$islets (Fig. 6b). Although metformin upregulated islet gene expression (Fig. 6b), no significant changes in expression of Gip, Cck, Pcl (also known as Pcsk1), proglucagon and peptide YY mRNA transcripts were observed in the upper or lower gastrointestinal tract of metformin-treated Ppard $^{+/+}$and Ppard $^{-/-}$mice (Fig. 6c, d).

\section{Discussion}

Our data demonstrate that metformin rapidly increases plasma levels of GLP-1, but not GIP or peptide YY, even in the absence of oral glucose administration. Given the potent actions of metformin on [1] suppression of hepatic glucose production and [2] peripheral glucose disposal, it is not a

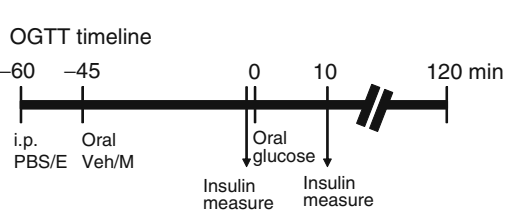

b

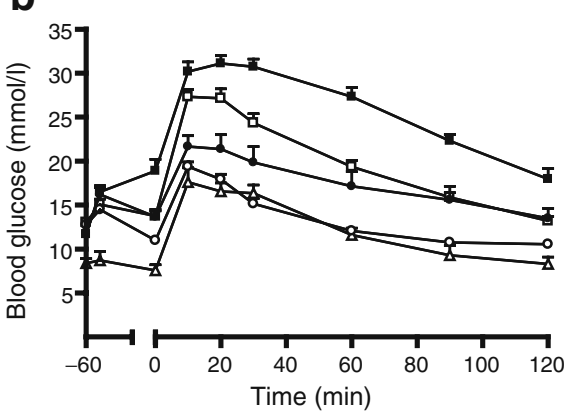

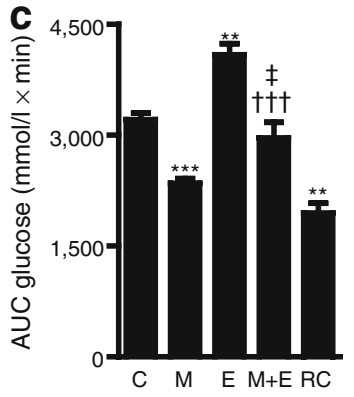

d

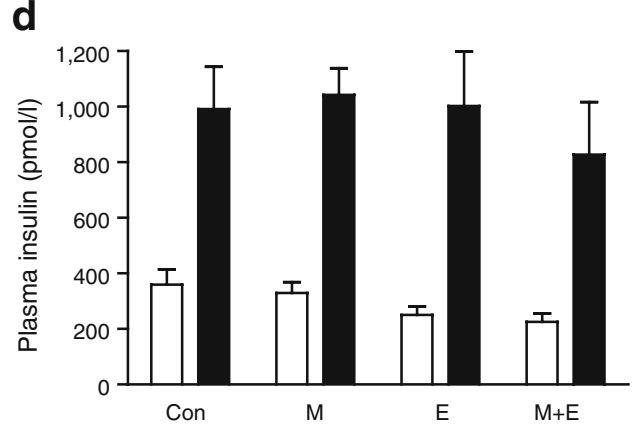

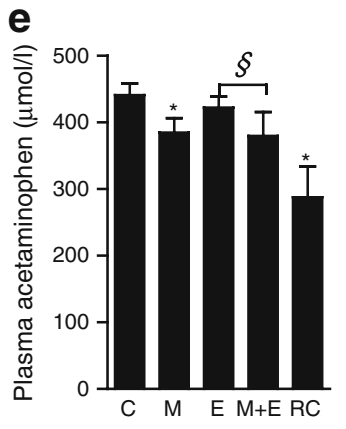

Fig. 4 The glucoregulatory actions of metformin in wild-type mice on high-fat diet in the presence or absence of the GLP1R antagonist exendin(9-39). Male C57BL/6 mice were placed on a high-fat diet $(60 \%$ energy from fat + sucrose) or kept on regular chow (RC) for 12 weeks, then fasted for $6 \mathrm{~h}$ and (a) injected with saline or exendin(939) (E, $0.1 \mathrm{mg} / \mathrm{kg}$ i.p.) at $t=-60 \mathrm{~min}$. Mice were administered vehicle (Veh; $0.5 \% \mathrm{wt} / \mathrm{vol}$. methylcellulose) or metformin (M; $75 \mathrm{mg} / \mathrm{kg}$ ) at $t=$ $-45 \mathrm{~min}$ by oral gavage. At $t=0$ mice were given a solution containing glucose + acetaminophen by oral gavage and blood glucose was measured from 0 to $120 \mathrm{~min}$. b OGTT results for control $(\mathrm{C}$; white squares), metformin (M; white circles), exendin(9-39) (E; black squares), $\mathrm{M}+\mathrm{E}$ (black circles) and $\mathrm{RC}$ (white triangles), with (c) mean AUC for glucose. d Plasma insulin was measured in plasma before $(t=0$, white bars $)$ and $10 \mathrm{~min}$ after $(t=10$, black bars $)$ glucose administration. e Gastric emptying was assessed indirectly by measuring plasma acetaminophen at $t=10 \mathrm{~min}$. ${ }^{*} p<0.05,{ }^{*} p<0.01$ and $* * * p<0.001$ vs control, ${ }^{\dagger \dagger} p<0.001$ vs exendin(9-39); ${ }^{\star} p<0.05$ vs metformin; ${ }^{\S} p=0.03$. $n=12-14$ mice per group 
a
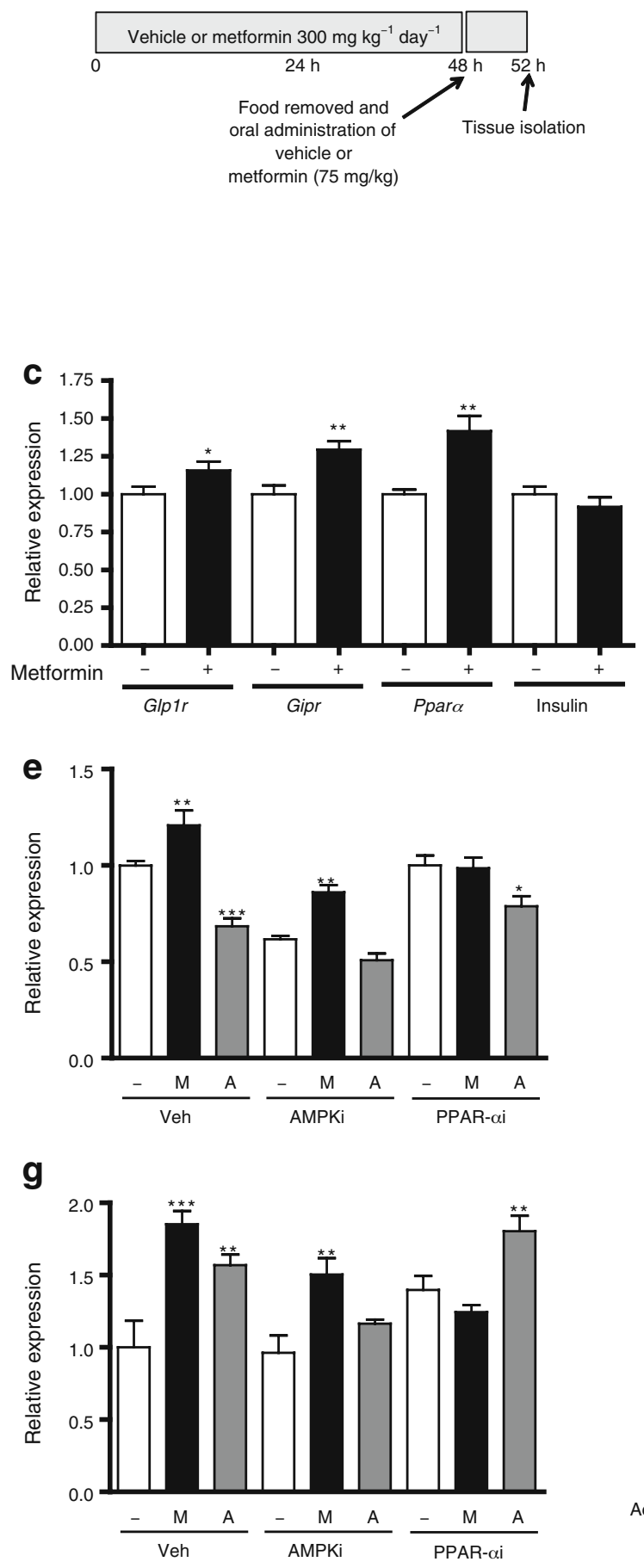

surprising that elimination of incretin receptor signalling fails to eliminate the salutary effects of metformin on oral glucose tolerance in normal mice or mice on a high-fat diet. These findings demonstrate that incretin receptors do not represent the dominant mechanism for metformin action on oral glucose tolerance in this acute experimental setting. b
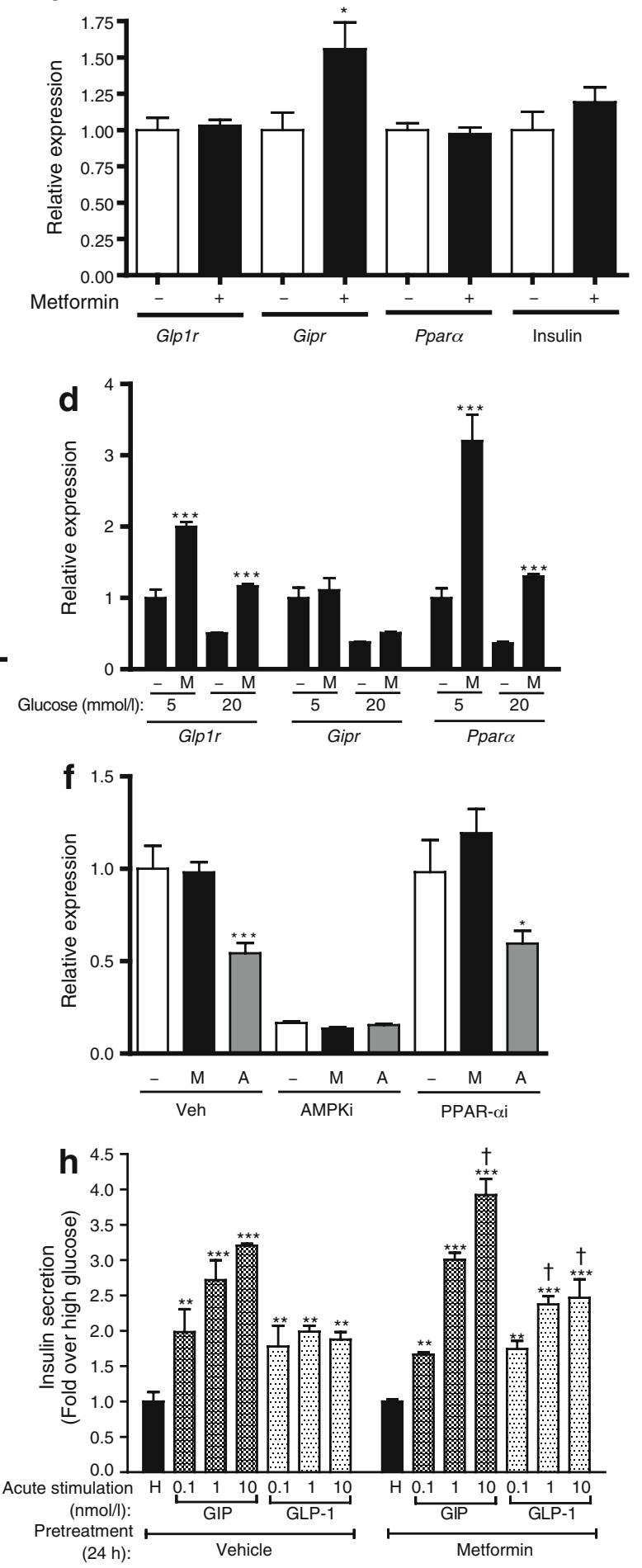

Moreover, incretin receptor knockout mice may exhibit a number of compensatory mechanisms that further complicate the study of incretin action in vivo [27]. Intriguingly, in the presence of the GLP1R antagonist exendin(9-39), metformin did not significantly reduce gastric emptying in moderately diabetic wild-type mice. Hence, we cannot rule 
Fig. 5 Metformin upregulates incretin receptor expression in islet cells in a PPAR- $\alpha$-dependent manner. Male C57BL/6 mice were treated with or without metformin in the drinking water as depicted (a). Gene expression was quantified by real-time PCR in RNA from pancreas (b) and freshly isolated islets (c) of metformin- (M) or vehicle (Veh)-treated mice. Transcript levels were expressed relative to levels in vehicle-treated mice. ${ }^{*} p<0.05$ and ${ }^{* *} p<0.01$ metformin vs corresponding vehicle-treated groups. $n=11-12$ mice (b) and $n=7-$ 8 islet preparations from individual mice (c). d Glp1r, Gipr and Ppard transcript levels were quantified by real-time PCR in RNA from INS-1 $832 / 3$ beta cells treated for $24 \mathrm{~h}$ with or without metformin $(1 \mathrm{mmol} / \mathrm{l})$ in serum-free media containing 5 or $20 \mathrm{mmol} / 1$ glucose. ${ }^{* * *} p<0.001$ metformin vs vehicle-treated groups. e Expression of Glp1r, (f) Gipr and (g) Ppara transcripts was quantified in INS-1 832/3 cells at $5 \mathrm{mmol} / \mathrm{l}$ glucose pre-treated for $15 \mathrm{~min}$ with vehicle (Veh; DMSO), the AMPK inhibitor (AMPKi; $20 \mu \mathrm{mol} / 1$ compound C), the PPAR- $\alpha$ inhibitor (PPAR- $\alpha \mathrm{i} ; 10 \mu \mathrm{mol} / 1 \mathrm{MK}-886$ ), followed by addition of metformin (M, $1 \mathrm{mmol} / \mathrm{l})$ or AICAR (A, $1 \mathrm{mmol} / \mathrm{l})$ for an additional $24 \mathrm{~h}$. Transcript levels were expressed relative to levels in vehicletreated controls for experiments. $* p<0.05,{ }^{* *} p<0.01$ and $* * * p<$ 0.001. h Cells were treated with or without metformin $(1 \mathrm{mmol} / \mathrm{l})$ for $24 \mathrm{~h}$ prior to assessment of insulin secretion in response to high glucose $(\mathrm{H}, 15 \mathrm{mmol} / \mathrm{l})$ or high glucose plus the indicated concentrations of GIP or GLP-1. Secreted insulin was normalised to insulin content and expressed relative to values obtained with corresponding high glucose controls. ${ }^{* *} p<0.01$ and ${ }^{* * *} p<0.001$ vs respective high glucose controls. ${ }^{\dagger} p<0.05$ vs dose-matched vehicle-treated condition. $n=2-3$ individual experiments, each with triplicate measurements

a
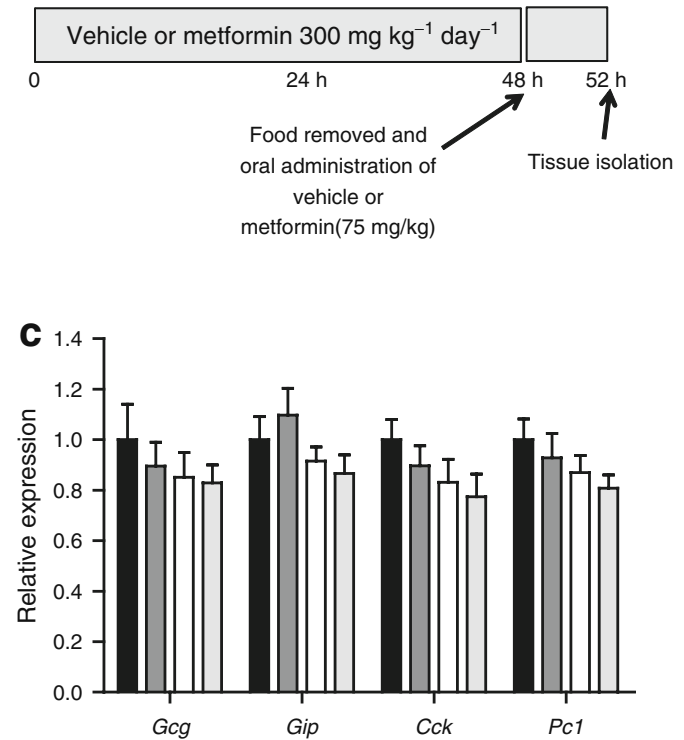

Fig. 6 Metformin regulates islet gene expression through a mechanism requiring PPAR- $\alpha$. a Male Pparo $^{+/+}$and littermate Pparo $^{-/-}$mice were administered drinking water containing metformin at $300 \mathrm{mg} / \mathrm{kg}$ daily or standard drinking water for $48 \mathrm{~h}$. At $4 \mathrm{~h}$ prior to killing of mice food was removed from cages and mice were given a low dose of metformin $(75 \mathrm{mg} / \mathrm{kg}$ ) or vehicle (water) by gavage. b Islets were isolated for quantification of gene expression by real-time PCR. Data were out a small contribution of GLP1R signalling to the actions of metformin on gastric motility. Furthermore, the majority of our studies involve acute metformin administration and so our data cannot rule out the possibility that signalling through the GLP1R might contribute more substantially to the chronic glucose-lowering actions of metformin in more severe models of hyperglycaemia.

The mechanisms coupling metformin action to rapid increases in total plasma GLP-1 immunoreactivity remain incompletely defined. Although metformin reduces plasma levels of DPP-4 activity in rodents and human participants, the available evidence suggests that metformin is not a direct inhibitor of DPP-4 activity [15, 16]. Our data are consistent with recent findings in rodents and humans, demonstrating that a single dose of metformin elevates plasma total GLP-1, but not GIP. Although our studies of short-term metformin administration did not result in significant changes in proglucagon gene expression in the murine gut, a different experimental paradigm and high-dose metformin administration did lead to increases in intestinal proglucagon gene expression in mice [28]. Experiments using enteroendocrine cell lines demonstrate that metformin is not a direct $\mathrm{L}$ cell secretagogue [29]. Moreover, induction of proglucagon biosynthesis in the gut does not explain the rapid and selective increase in plasma GLP-1, but not GIP or peptide
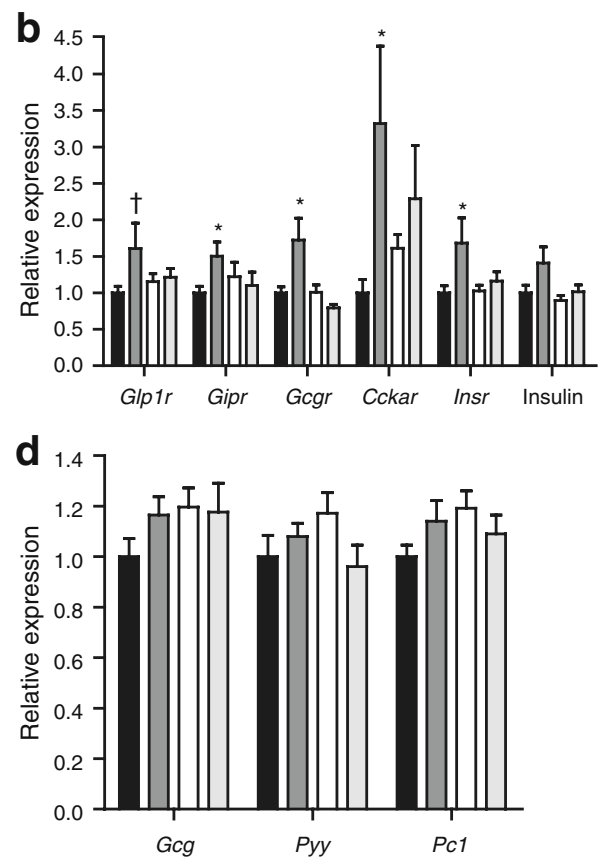

generated from $n=6-8$ individual islet preparations. $* p<0.05$ vs Ppard $^{+/+}$vehicle; ${ }^{\dagger} p<0.06$. c mRNA levels were quantified for $G c g$, Gip, Cck and $P c 1$ in duodenum, and (d) for Gcg, Pyy and $P c 1$ in colon of vehicle vs metformin-treated Ppard $^{+/+}$and littermate Ppard $^{-1-}$ mice. Light grey bars, metformin-treated Pparo $^{-1-}$; dark grey bars, metformintreated Ppard $^{+/+}$; white bars, vehicle-treated Ppard $^{-1-}$; black bars, vehicle-treated Ppard $^{+/+} . n=9-10$ mice per group 
YY, another enteroendocrine-derived peptide that is cosecreted with GLP-1 from subsets of L cells [30]. Hence, the molecular mechanisms linking metformin exposure to increased circulating levels of GLP-1 require further study.

The effects of metformin on islets have been somewhat contradictory, with some reports demonstrating that metformin inhibits insulin secretion [31], impairs glucoseresponsivity and enhances susceptibility to apoptosis [32]. In contrast, metformin was also reported to improve insulin secretion, increase insulin gene expression and insulin content, and reduce islet apoptosis in human islets exposed to high glucose [33]. These discrepancies possibly reflect variation in experimental models and culture conditions, species-specific differences, doses of metformin and duration of metformin exposure, and require further study. In the second section of our study, we demonstrated that subchronic treatment of mice with metformin leads to enhanced expression of the Glp1r and Gipr genes in murine islets. Pan and colleagues indirectly implicated a role for AMPK in the actions of metformin on islet gene expression via their demonstration that AICAR mimicked the actions of metformin on Glplr and Gipr mRNA transcripts in INS1 cells [26]. In contrast, our data demonstrate that AICAR downregulates Glp1r and Gipr mRNA transcripts in INS-1 $832 / 3$ beta cells. Furthermore, the actions of metformin in increasing Glp1r mRNA transcripts were not diminished by the AMPK inhibitor compound C. Taken together, these findings strongly suggest that the inductive effects of metformin on Glplr expression are not mediated through an AMPK-dependent pathway.

A role for PPAR- $\alpha$ in the control of Gipr gene expression has previously been reported in studies of INS $(832 / 13)$ cells. Thus Lynn and colleagues demonstrated that the PPAR- $\alpha$ agonist WY14643 increased Gipr gene expression in BRIN-D11 beta cells and in rat islets [34]. Conversely, the PPAR- $\alpha$ antagonist MK-886 and a dominant negative Ppar $\alpha$ cDNA reduced Gipr expression under conditions of low glucose in transfected INS(832/13) cells [34]. Our data demonstrate that PPAR $\alpha$ is essential for the upregulating effects of metformin on multiple receptor genes thought to play a role in islet function, including Glp1r, Gipr, Gcgr, Cckar and Insr. Consistent with the observed changes in incretin receptor expression, metformin treatment moderately enhanced the relative insulinotropic response to GLP-1 and GIP in islet cells. Intriguingly, the related nuclear receptor, PPAR- $\gamma$, has recently been implicated in control of islet Gipr expression [35]. The precise molecular mechanisms through which metformin recruits PPAR- $\alpha$ to control islet gene expression require further elucidation.

In summary, we show here that metformin acutely and differentially increases plasma levels of GLP-1 but not those of GIP in mice. Moreover, metformin produces robust induction of islet gene expression and incretin responsiveness. Although the glucoregulatory actions of metformin on glucose tolerance and inhibition of food intake are not completely eliminated in incretin receptor knockout mice, the extent to which metformin exerts its metabolic actions in part through incretin receptors in more severely diabetic models that are resistant to suppression of hepatic glucose production merits further exploration. To resolve the question of whether chronic metformin therapy is associated with greater dependence upon the incretin axis for glucoregulation in type 2 diabetic human patients, more effective incretin antagonists would need to be developed for human use, and so this question remains unanswered. Taken together, our findings provide new insights into the relationship between metformin, plasma levels of incretins and the expression of islet receptors transducing the actions of incretins in vivo.

Acknowledgements This study was supported by a Canadian Institutes of Health Research (CIHR) operating grant MOP82700. A. Maida was supported in part by a CIHR doctoral student award.

Duality of interest D. J. Drucker consults for several companies developing incretin-based therapeutics as outlined in detail at www. glucagon.com/druckerlab.html. All other authors declare that there is no duality of interest associated with this manuscript.

\section{References}

1. Nathan DM, Buse JB, Davidson MB et al (2009) Management of hyperglycaemia in type 2 diabetes mellitus: a consensus algorithm for the initiation and adjustment of therapy. A consensus statement from the American Diabetes Association and the European Association for the Study of Diabetes. Diabetologia 52:17-30

2. Hundal RS, Krssak M, Dufour S et al (2000) Mechanism by which metformin reduces glucose production in type 2 diabetes. Diabetes 49:2063-2069

3. Zhou G, Myers R, Li Y et al (2001) Role of AMP-activated protein kinase in mechanism of metformin action. J Clin Invest 108:1167-1174

4. Shaw RJ, Lamia KA, Vasquez D et al (2005) The kinase LKB1 mediates glucose homeostasis in liver and therapeutic effects of metformin. Science 310:1642-1646

5. He L, Sabet A, Djedjos S et al (2009) Metformin and insulin suppress hepatic gluconeogenesis through phosphorylation of CREB binding protein. Cell 137:635-646

6. Takashima M, Ogawa W, Hayashi K et al (2010) Role of KLF15 in regulation of hepatic gluconeogenesis and metformin action. Diabetes 59:1608-1615

7. Foretz M, Hebrard S, Leclerc J et al (2010) Metformin inhibits hepatic gluconeogenesis in mice independently of the LKB1/ AMPK pathway via a decrease in hepatic energy state. J Clin Invest 120:2355-2369

8. Kalender A, Selvaraj A, Kim SY et al (2010) Metformin, independent of AMPK, inhibits mTORC1 in a rag GTPasedependent manner. Cell Metab 11:390-401

9. Muller WA, Faloona GR, Aguilar-Parada E, Unger RH (1970) Abnormal alpha-cell function in diabetes. Response to carbohydrate and protein ingestion. N Engl J Med 283:109-115 
10. Drucker DJ, Nauck MA (2006) The incretin system: glucagon-like peptide-1 receptor agonists and dipeptidyl peptidase-4 inhibitors in type 2 diabetes. Lancet 368:1696-1705

11. Lenhard JM, Croom DK, Minnick DT (2004) Reduced serum dipeptidyl peptidase-IV after metformin and pioglitazone treatments. Biochem Biophys Res Commun 324:92-97

12. Green BD, Irwin N, Duffy NA, Gault VA, O'Harte FP, Flatt PR (2006) Inhibition of dipeptidyl peptidase-IV activity by metformin enhances the antidiabetic effects of glucagon-like peptide-1. Eur J Pharmacol 547:192-199

13. Lindsay JR, Duffy NA, McKillop AM et al (2005) Inhibition of dipeptidyl peptidase IV activity by oral metformin in type 2 diabetes. Diabet Med 22:654-657

14. Cuthbertson J, Patterson S, O'Harte FP, Bell PM (2009) Investigation of the effect of oral metformin on dipeptidylpeptidase-4 (DPP4) activity in type 2 diabetes. Diabet Med 26:649-654

15. Hinke SA, Kuhn-Wache K, Hoffmann T, Pederson RA, McIntosh CH, Demuth HU (2002) Metformin effects on dipeptidylpeptidase IV degradation of glucagon-like peptide-1. Biochem Biophys Res Commun 291:1302-1308

16. Yasuda N, Inoue T, Nagakura T et al (2002) Enhanced secretion of glucagon-like peptide 1 by biguanide compounds. Biochem Biophys Res Commun 298:779-784

17. Mannucci E, Ognibene A, Cremasco F et al (2001) Effect of metformin on glucagon-like peptide 1 (GLP-1) and leptin levels in obese nondiabetic subjects. Diabetes Care 24:489-494

18. Mannucci E, Tesi F, Bardini G et al (2004) Effects of metformin on glucagon-like peptide-1 levels in obese patients with and without type 2 diabetes. Diabetes Nutr Metab 17:336-342

19. Hansotia T, Baggio LL, Delmeire D et al (2004) Double incretin receptor knockout (DIRKO) mice reveal an essential role for the enteroinsular axis in transducing the glucoregulatory actions of DPP-IV inhibitors. Diabetes 53:1326-1335

20. Villhauer EB, Brinkman JA, Naderi GB et al (2003) 1-[[(3-hydroxy1-adamantyl)amino]acetyl]-2-cyano-(S)-pyrrolidine: a potent, selective, and orally bioavailable dipeptidyl peptidase IV inhibitor with antihyperglycemic properties. J Med Chem 46:2774-2789

21. Maida A, Lovshin JA, Baggio LL, Drucker DJ (2008) The glucagon-like peptide-1 receptor agonist oxyntomodulin enhances $\beta$-cell function but does not inhibit gastric emptying in mice. Endocrinology 149:5670-5678

22. Kosaka T, Okuyama R, Sun W et al (2005) Identification of molecular target of AMP-activated protein kinase activator by affinity purification and mass spectrometry. Anal Chem 77:2050-2055

23. Nauck MA, Niedereichholz U, Ettler R et al (1997) Glucagon-like peptide 1 inhibition of gastric emptying outweighs its insulinotropic effects in healthy humans. Am J Physiol 273:E981-E988
24. Gunnarsson PT, Winzell MS, Deacon CF et al (2006) Glucoseinduced incretin hormone release and inactivation are differently modulated by oral fat and protein in mice. Endocrinology 147:3173-3180

25. Winzell MS, Ahren B (2004) The high-fat diet-fed mouse: a model for studying mechanisms and treatment of impaired glucose tolerance and type 2 diabetes. Diabetes 53(Suppl 3): S215-S219

26. Pan QR, Li WH, Wang H et al (2009) Glucose, metformin, and AICAR regulate the expression of $\mathrm{G}$ protein-coupled receptor members in INS-1 beta cell. Horm Metab Res 41:799-804

27. Pederson RA, Satkunarajah M, McIntosh CH et al (1998) Enhanced glucose-dependent insulinotropic polypeptide secretion and insulinotropic action in glucagon-like peptide 1 receptor $^{-/}$ mice. Diabetes 47:1046-1052

28. Migoya EM, Bergeron R, Miller JL et al (2010) Dipeptidyl peptidase-4 inhibitors in combination with metformin result in an additive increase in active GLP-1 concentrations. Clin Pharmacol Ther (in press)

29. Lauffer L et al (2009) Metformin activates the AMPK pathway and improves survival of murine and human L-cells but does not directly increase GLP-1 secretion. Diabetologia 52(Suppl 1):OP33, Abstract

30. Dumoulin V, Moro F, Barcelo A, Dakka T, Cuber JC (1998) Peptide YY, glucagon-like peptide-1, and neurotensin responses to luminal factors in the isolated vascularly perfused rat ileum. Endocrinology 139:3780-3786

31. Leclerc I, Woltersdorf WW, da Silva XG et al (2004) Metformin, but not leptin, regulates AMP-activated protein kinase in pancreatic islets: impact on glucose-stimulated insulin secretion. Am J Physiol Endocrinol Metab 286:E1023-E1031

32. Kefas BA, Cai Y, Kerckhofs K et al (2004) Metformin-induced stimulation of AMP-activated protein kinase in beta-cells impairs their glucose responsiveness and can lead to apoptosis. Biochem Pharmacol 68:409-416

33. Marchetti P, del Guerra S, Marselli L et al (2004) Pancreatic islets from type 2 diabetic patients have functional defects and increased apoptosis that are ameliorated by metformin. J Clin Endocrinol Metab 89:5535-5541

34. Lynn FC, Thompson SA, Pospisilik JA et al (2003) A novel pathway for regulation of glucose-dependent insulinotropic polypeptide (GIP) receptor expression in beta cells. FASEB J 17:91-93

35. Gupta D, Peshavaria M, Monga N, Jetton TL, Leahy JL (2010) Physiologic and pharmacologic modulation of GIP receptor expression in $\beta$-cells by PPAR $\gamma$ signaling: possible mechanism for the GIP resistance in type 2 diabetes. Diabetes 59:1445-1450 